\title{
ASSIMILAÇÃO E IDENTIDADE EM HIROSHI SAITO ${ }^{12}$ ASSIMILATION AND IDENTITY IN HIROSHI SAITO
}

\author{
Aline de Sá Cotrim ${ }^{3}$
}

Resumo: Este artigo objetiva analisar a abordagem do sociólogo Hiroshi Saito sobre imigração japonesa no Brasil a partir de três artigos publicados entre 1947 e 1953 . A categoria chave do autor é a assimilação, comum na época dentre os estudos de imigração para expressar a adequação dos migrantes à sociedade receptora. Saito busca compreender se e como a assimilação estava se desenvolvendo, quais eram as reações a ela, e de que forma ela influenciava a personalidade dos imigrantes. Ele encontra, por exemplo, entre diferentes gerações de imigrantes japoneses um grupo composto de pessoas que não se identificavam como japoneses nem brasileiros, caracterizado por ele como "marginal", conceito este que podemos relacionar à própria trajetória pessoal de Saito. Palavras-chaves: Hiroshi Saito. Assimilação. Imigração Japonesa. Imigrante Marginal. História das Ciências Sociais.

\begin{abstract}
This article aims to analyze the approach of the sociologist Hiroshi Saito on Japanese immigration in Brazil from three articles published by him between 1947 and 1953. The key category for him is the assimilation, common at that moment among the immigration studies to express the adequacy of the migrants to the receiving society. Saito seeks to understand if and how assimilation was developing, what were the reactions to it, and how it influenced the personality of immigrants. He discovers between different generations of Japanese immigrants, for example, a group composed of people who did not identify themselves neither as Japanese nor as Brazilians, characterized by him as "marginal", a concept that we can relate to Saito's own personal trajectory.
\end{abstract}

Keywords: Hiroshi Saito. Assimilation. Japanese Immigration. Marginal Immigrant. History of Social Sciences.

1 Artigo submetido em 04/11/2019 e aprovado em 16/04/2020.

2 Esta pesquisa é parte da minha dissertação de mestrado defendida em 2016 no Programa de Pós-Graduação em História das Ciências e da Saúde da Casa de Oswaldo Cruz (COC), e teve apoio da bolsa FIOCRUZ.

3 Doutoranda do Programa de Pós-Graduação em História, Política e Bens Culturais (PPHPBC), do CPDOC FGV. Mestre em História das Ciências e da Saúde pelo Programa de Pós-Graduação em História das Ciências e da Saúde da Casa de Oswaldo Cruz (COC); adscotrim@gmail.com. (ORCID iD: https://orcid.org/0000-0001-7991-5243). 


\section{Introdução}

A imigração japonesa foi um dos movimentos migratórios mais importantes da história do Brasil, porém a capacidade de adaptação destas pessoas à sociedade brasileira foi constantemente questionada desde seu início em 1908. Este contexto gerou inúmeros estudos na área de Ciências Sociais entre as décadas de 1940 e 1960, que investigavam como acontecia o processo de assimilação dos estrangeiros ao novo local de moradia e a relação com a comunidade local.

Entre estes estudos, temos os do sociólogo Hiroshi Saito (1919-1983), com dados, entrevistas e conceitos que investigam a inserção dos japoneses e mostram benefícios que eles traziam para o país. Ao analisar este processo de assimilação, Saito identifica exemplos de reações contra e que nem todos estavam no mesmo estágio deste processo. Este é o caso do grupo intermediário, composto nem de idosos nem de jovens, caracterizado por ele como "marginal", conceito que podemos relacionar a própria trajetória pessoal de Saito.

Considerando isso, trago aqui três artigos onde fica clara a análise de Saito sobre a relação entre o processo de assimilação e a definição de imigrante marginal. Primeiro, apresentarei quem foi Hiroshi Saito, as principais obras e a definição do conceito de assimilação. Segundo, analisarei seu artigo publicado em coautoria com Emilio Willems, sobre a sociedade secreta Shindô-Renmei. Na sequência, trato de um artigo sobre os casos de suicídio entre os imigrantes japoneses. Por último, um texto escrito em coautoria com o japonês Seiichi Izumi, onde eles apontam uma camada de imigrantes japoneses como "marginais". Os três artigos foram escritos quando Saito ainda era estudante de Ciências Sociais e seus estudos se conectavam com os seus questionamentos pessoais. Sendo assim, na conclusão, conecto as análises de Saito com sua história de vida, e argumento que seu próprio processo de assimilação influenciou tanto sua identidade de imigrante japonês, como de sociólogo brasileiro.

\section{Hiroshi Saito: vida e obra}

Nascido em Uriuno, no Japão, Hiroshi Saito imigra para o Brasil com a família em 1933 (CASTRO, 1994). Entre 1933 e 1935, Saito fez um curso na Escola Agrícola M'Boy, em São Paulo, que era tida como "assimilacionista" e objetivava formar uma elite especializada para administrar as colônias agrícolas. Ela ensinava história e geografia do Brasil, português, japonês, legislação e contabilidade agrícola, e agricultura em geral (TANIGUTI \& JESUS, 2012).

No início da década de 1940, Saito conhece o sociólogo Emilio Willems (19051997), de quem foi informante em suas pesquisas. Em 1947, Saito entra como aluno na Escola Livre de Sociologia e Política de São Paulo (ELSP), onde se forma em 1951. Ele faz ali o mestrado em Ciências Sociais entre 1954 e 1956, sob a orientação de Donald Pierson (1900-1995), e defende o doutorado em economia, em 1960, na Universidade de Kobe, 
no Japão. Saito teve papel ativo na comunidade japonesa, sendo um dos fundadores do Centro de Estudos Nipo-Brasileiros (CEBN), em 1965 (CASTRO, 1994).

No momento de entrada de Saito na universidade, havia no Brasil, e em outros lugares do mundo, algumas concepções diferentes da forma como se deveria estudar e fazer sociologia. Na ELSP, a sociologia era concebida de forma pragmática, formando quadros técnicos para o estudo e intervenção política na comunidade analisada. $\mathrm{O}$ foco da instituição pairava justamente sobre a pesquisa empírica e seguia um modelo norte-americano, principalmente no que concernia às contratações de professores estrangeiros. Na Faculdade de Filosofia, Ciências e Letras (FFCL), da Universidade São Paulo (USP), por outro lado, prevalecia a preocupação com uma formação mais "filosófica", voltada para reflexões teóricas e gerais, e tinha uma forte influência do modelo francês de ensino. Ela tinha por objetivo principal formar uma elite de professores para a educação básica e acadêmicos que pensassem a sociedade brasileira (LIMONGI, 1989, pp. 220-222; COTRIM, 2016).

Um dos seus livros mais conhecidos é O Cooperativismo na Região de Cotia: estudo de transplantação cultural (1956), que possui uma segunda edição de 1964. O livro traz uma pesquisa realizada por meio de entrevistas e análise de dados, e objetiva investigar como o cooperativismo foi trazido da cultura japonesa para a brasileira e implantado na colônia japonesa de Cotia (SP), pensando as condições de estabelecimento dos imigrantes no Brasil, a relação com moradores locais, as mudanças dos padrões culturais (COTRIM, 2016).

Saito publicou também o livro O japonês no Brasil: estudo de mobilidade e fixação (1961), uma análise abrangente dos processos de deslocamento e estabelecimento dos japoneses no país com base em pesquisas realizadas por ele. Neste, ele aborda as características da adaptação do imigrante no Brasil, especialmente a adaptação física e ao meio, que teria auxiliado a mobilidade social, espacial e ocupacional destes indivíduos. Esta mobilidade, segundo Saito, seria uma comprovação da assimilação dos imigrantes à sociedade brasileira, pois o mesmo processo era encontrado entre os brasileiros na década de $1950^{4}$.

Ainda, destaco o livro Assimilação e Integração dos Japoneses no Brasil, organizado por Saito e Takashi Mayeama, em 1973. O trabalho possui artigos de vários cientistas sociais brasileiros e estrangeiros, como Tomoo Handa, Zempati Ando, Teiiki Suzuki, Ruth Cardoso e Egon Schaden. Os textos são sobre temas que circundam a imigração japonesa, como a sua história, o desenvolvimento econômico, a religião e a adaptação, além de artigos que comparam a aculturação de alemães e japoneses no país.

Em seus estudos, Saito tinha uma preocupação comum: o processo de assimilação dos imigrantes japoneses. Como eles estavam se integrando à sociedade brasileira,

4 Donald Pierson ao resenhar o livro afirma que ele revelava "a vantagem metodológica de serem combinadas, em trabalhos de pesquisa, a intimidade e a objetividade" (1961, p. 165). O primeiro lhe traria a experiência (visto que Saito era um imigrante japonês), e o segundo traria o olhar realista perante a sociedade adquirido em seus anos de estudos. 
e os traços culturais que estavam abandonando e adotando para tal. Ele define que este o processo é a:

Transformação em que a comunidade, caracterizada no início pela reconstituição de elementos e padrões japoneses, passa depois a vincular-se intimamente à sociedade dominante, apresentando simultaneamente o caráter de ambas as culturas. (SAITO, 1961, p. 212)

Em outras palavras, o indivíduo que passou pelo processo de assimilação teria marcas das culturas com as quais teve contato intenso, mesmo que a cultura hegemônica estivesse mais presente no seu dia-a-dia, criando, assim, uma nova cultura. Este processo aconteceria de formas distintas entre as diferentes gerações de imigrantes, pois para a população mais nova ele seria menos difícil, visto que ela teria menos contato com a sua cultura de origem e menos traços a serem abandonados.

O processo de assimilação, para Saito, segue o modelo concebido por Robert Park e Ernest Burgess (2014), dividido em quatro etapas: competição, conflito, acomodação e assimilação. A competição é a "luta pela existência" e passa despercebida na maior parte do tempo. Em momentos de crise, quando os indivíduos estão conscientes da busca pelo controle das condições de sua vida, há o conflito. A mudança da competição para o conflito pode ser descrita como um processo político, podendo levar a momentos de mudança, como guerras ou eleições, com tomadas de decisões, que, se aceitas, é encerrado o conflito chegando-se à acomodação. Esta etapa "é o processo através do qual os indivíduos e grupos fazem os ajustes internos necessários para as situações sociais que foram criadas pela competição e conflito" (PARK \& BURGESS, 2014, p. 131), estabelecendo um novo modus vivendi. A assimilação, último nível do processo, implica em mudanças mais profundas na sociedade, levando à transformação gradual das personalidades sob o contato mais íntimo e concreto (PARK \& BURGESS, 2014). Esta concepção do processo de assimilação do imigrante aparece nos estudos de Saito, ao interpretar a interação do japonês com a cultura brasileira, contudo, para ele, o resultado final seria um indivíduo em contato com ambas as culturas, com um equilíbrio entre elas (COTRIM, 2016).

\section{A pesquisa sobre a Shindô-Renmei}

Em 1947, no mesmo ano em que inicia os seus estudos na ELSP, Saito publica um artigo na revista Sociologia em coautoria com Emílio Willems intitulado "Shindô-Renmei: um problema de aculturação". Neste eles analisam a formação da sociedade secreta Shindô-Renmei dentro da colônia japonesa no Brasil, no final da Segunda Guerra Mundial.

A associação foi oficializada em 1945, em meio à implantação das leis de nacionalização do Estado Novo (HATANAKA, 2002). A legislação estabelecia a proibição, no território nacional, de escolas estrangeiras e jornais que não editados em português, justamente para fortalecer a cultura nacional e forçar a assimilação dos imigrantes. Com a entrada do Brasil na Segunda Guerra Mundial, em 1942, a repressão contra japoneses e 
alemães que descumprissem essas leis aumentaram, por conta da imagem que havia deles como inimigos da nação (SEYFERTH, 1997). Como a maioria dos imigrantes japoneses não dominava a língua portuguesa, ela permaneceu isolada da sociedade brasileira e ficou mais suscetível à manipulação de grupos nacionalistas (WILLEMS \& SAITO, 1947).

Durante guerra, os japoneses sofreram com o preconceito antinipônico, havendo casos de brigas de rua, prisões e batidas policiais em residências (CASTRO, 1994; TANIGUTI, 2015). O fato da sua "nação adotiva" estar lutando contra a sua "nação de origem" tornava a vida no Brasil desconfortável para a maioria dos japoneses. Saito (1961) destaca que a guerra é um momento de ruptura para a comunidade japonesa no país, pois, de um lado, parte dos imigrantes não acreditava nas notícias da derrota do Japão e condenava quem afirmasse o contrário. De outro, outra parte aceitava a derrota e não avistava mais o retorno ao país natal, devastado pela guerra, levando-os a planejar a permanência a longo prazo no Brasil.

Para além da associação, o artigo Willems e Saito se preocupa em entender o processo de assimilação dos imigrantes. Segundo os autores, "migrações entre meios culturalmente diferentes suscitam, invariavelmente, o problema da reorganização social dos imigrantes", o que poderia gerar graves problemas mentais, traduzindo-se inclusive em "comportamentos indesejáveis" (WILLEMS \& SAITO, 1947, p. 133). Eles afirmam que a preservação ou defesa da cultura é necessária como instrumento de sobrevivência dos imigrantes, pois o abandono de determinados traços culturais traz conflitos mentais e desorganização social do grupo. Sendo assim, "não pode causar surpresa que a assimilação não possa desencadear propriamente entusiasmo em grupo nenhum, pois a assimilação se compara a uma operação muito dolorosa, muito demorada e feita sem anestesia" (WILLEMS \& SAITO, 1947, p. 133). Esse processo contempla revoltas e a formação de grupos que se oponham radicalmente às mudanças, como é o caso da Shindô-Renmei.

Os líderes da associação seriam menos adaptados e com mais projetos de retorno ao Japão. Inicialmente, desejavam expandir o "espírito japonês", que seria um "modo de vida japonês", que os diferenciaria de outros grupos étnicos, e um tipo de comportamento ideal, além do desejo de colaborar com a criação da "Grande Ásia Oriental" e da preocupação em manter os jovens em contato a cultura japonesa. A Shindô-Renmei distribuía panfletos valorizando a manutenção das tradições japonesas e defendia o apoio incondicional ao Imperador (WILLEMS, \& SAITO, 1947).

De acordo com os associados, a função dos imigrantes seria adquirir recursos para o desenvolvimento do Japão. O estabelecimento dos japoneses no Brasil seria apenas temporário e o retorno era inquestionável. Contudo, com a derrota do Japão e a destruição de parte do seu território, o retorno tornou-se inviável, fazendo com que a Shindô-Renmei perdesse o seu principal argumento contra a assimilação. Por essa razão, ela começou a divulgar informações falsas sobre a vitória do Japão.

Instalou-se um conflito na comunidade japonesa no país, pois aqueles que falavam a língua portuguesa obtinham informações para além daquelas noticiadas pela associação, tomando conhecimento da derrota do Japão (eles eram chamados de "derrotistas"). Ao 
tentarem divulgar essas notícias, eram ameaçados, sendo alguns deles, inclusive, torturados e assassinados pela Shindô-Renmei (WILLEMS \& SAITO, 1947; TANIGUTI, 2015). Estes conflitos foram reforçados pela proibição de jornais em língua japonesa e o consequente isolamento desses imigrantes em relação à sociedade brasileira e ao mundo. Hatanaka (2002) descreve casos de exclusão social de famílias e pessoas que não acreditavam na vitória do Japão dentro das comunidades agrícolas. Elas eram ignoradas pelos vizinhos, perdiam o direito de participar das assembleias e algumas se suicidaram. A existência da Shindô-Renmei e as ações contra e a favor dela são exemplos de como o processo de assimilação era tenso e havia reações contra ele.

$\mathrm{O}$ artigo de Willems e Saito apresenta questões presentes em outros escritos de Saito. O suicídio entre os imigrantes japoneses, por exemplo, tema de artigo publicado pouco depois, seria consequência da não assimilação de determinados indivíduos. A questão diferença geracional está presente no artigo publicado com Seiichi Izumi em 1953, com dados sobre o nível de assimilação dos indivíduos da primeira, segunda e terceira gerações (COTRIM, 2016). Além disso, as vantagens econômicas e sociais trazidas pelos imigrantes japoneses para a sociedade brasileira estão presentes na análise da Cooperativa Agrícola de Cotia (SAITO, 1956) e da mobilidade social (SAITO, 1961). Não obstante, o tema mais constante é a assimilação destes estrangeiros e a preocupação em identificar possíveis conflitos sociais e geracionais dentro dos grupos e com a sociedade local.

\section{O artigo sobre o suicídio e a cultura}

Conforme comentado no artigo de Saito e Willems, o processo de assimilação era doloroso e lento, e alguns imigrantes não conseguiam enfrentá-lo e no desespero se suicidavam. Este é o tema do artigo publicado por Saito, em 1953, na revista Sociologia. No texto, Saito traz dados de casos de suicídio entre os imigrantes japoneses, entendendo o suicídio como uma anomia da sociedade moderna.

Segundo Durkheim, quanto mais enfraquecido for um grupo, menos dependente dele é um determinado indivíduo, e mais dependente de si mesmo e sozinho ele é. Quando a sociedade se vê perturbada pela modernidade ou por uma mudança brusca, como a migração, ela tem menos mecanismos de controle dos seus indivíduos. Essa desorganização social e a maior pré-disposição à anomia geram aumento de casos de suicídios (DURKHEIM, 2002).

Saito inicia apresentando dados quantitativos que mostram que a taxa de suicídio, nos Estados Unidos, entre imigrantes e seus descendentes é mais alta do que entre a população nativa. De acordo com Ruth Cavan (1928 in SAITO, 1953, p. 109), o estrangeiro luta muito tempo para se adaptar ao novo meio, e ele só abandona a possibilidade do ato de desespero, em média, dez anos e meio após a sua chegada. Em estudo semelhante, Roger Bastide (1951), ao estudar os casos de suicídio entre os habitantes de São Paulo, conclui que a maior taxa de suicídio seria entre os alemães, italianos e portugueses. 
A taxa de suicídios dos estrangeiros era mais elevada também quando comparada aos números de seus países de origem. Segundo Saito:

Esta curiosa tendência não é senão um dos reflexos de uma série de conflitos que o imigrante deve enfrentar no decorrer do processo de ajustamento ao novo meio. Como o contato com a cultura estranha implica, nos imigrantes, a reorganização de sua personalidade, surgem, muitas vezes, graves perturbações mentais. São desajustamentos psíquicos, resultantes do conflito cultural a que são expostos os homens marginais. (SAITO, 1953, p. 110)

Fazendo uso do conceito de "homem marginal", Saito entende que estes imigrantes estariam numa situação de limbo, na qual não pertenceriam nem à sociedade japonesa, nem à brasileira. De acordo com Stonequist (1935), o homem marginal estaria presente em situações biculturais ou multiculturais ${ }^{5}$, sendo forçado a escolher uma cultura (em geral, a predominante). Saito continua a questão do suicídio fazendo suas as palavras de Stonequist:

A incapacidade para diagnosticar a fonte do conflito, a convicção de enfrentar um muro intransponível e os malogros pessoais avassalam o indivíduo. O conflito mental conduz ao desânimo e talvez ao desespero. Para o adulto, significa isso uma desintegração da "organização da vida" do indivíduo - essa trama de atitudes e valores em que tem o indivíduo o seu ser e através da qual ele realiza seus desígnios. Na sua forma extrema, resulta isto em desorganização mental e suicídio. (STONEQUIST, 1948. apud SAITO, 1953, p. 110)

Saito mostra que a taxa de suicídio entre os imigrantes japoneses é mais alta do que entre os brasileiros (e também entre a população do Japão). Segundo Bastide (1951, p. 47), "há simbiose entre os fatores individuais e os fatores coletivos: o social age através do psíquico, o psíquico é ajudado ou entravado pelo social". Isso é, o suicídio é uma junção de questões íntimas, da mente do próprio indivíduo, com fatores sociais, como a desorganização da sociedade e uma mudança brusca de ambiente ou padrão cultural. No íntimo do imigrante, os questionamentos e a solidão são reforçados pela sua presença num país estrangeiro com hábitos culturais diferentes dos seus.

Para além disso, na cultura japonesa, "a falta de cumprimento de um dever ou uma censura pela sociedade é um ato em contradição com a moral, basta para que se pratique o suicídio a fim de que o seu nome não fique 'sujo' e sua honra seja salva” (SAITO, 1953, p. 112). Esta seria uma forma de assumir a responsabilidade e justificar falhas na conduta de uma pessoa. Portanto, a alta taxa de casos de suicídio entre os imigrantes japoneses se explicaria pela chave da cultura, na qual os padrões, as causas e os meios dos suicídios

5 Situações biculturais ou multiculturais se referem a contextos sociais em que há mais de uma cultura predominante, como nas colônias imigrantes. 
comporiam também uma forma de reforçar a cultura de origem. Ao se encontrar num meio estranho e de difícil adaptação, sem a possibilidade de retorno pela falta de recursos, o imigrante enxergaria no suicídio a única forma de honrar e reafirmar as suas origens perante a si e a outros. Contudo, não necessariamente o suicídio é um ato calculado e racional, retirando da cultura parte de sua "responsabilidade".

A pesquisa do Saito foi feita a partir da análise das notícias do Jornal Paulista, periódico que circulava dentro da comunidade japonesa no país. Ele consultou jornais entre janeiro de 1947 e agosto de 1952, e foram encontrados relatos de 74 suicídios e quatro tentativas, o que resulta numa média de 13,86 suicídios por ano ${ }^{6}$. No que toca a forma de suicídio, 58 pessoas utilizaram algum tipo de veneno, certamente pela facilidade de acesso a produtos químicos na agricultura. Ainda, entre os motivos para cometerem o suicídio estão os de "amor" (16 casos), de questões de família (13) e de questão de honra (10 casos), os três relacionados a questões culturais.

Muitos dos problemas familiares, assim como afetivos, surgiam por desavenças entre pais e filhos em relação à escolha do parceiro. Por exemplo, quando o filho que se apaixona por uma brasileira, pois o namoro entre japoneses e brasileiros era censurado pela comunidade. Além disso, Saito (1953) encontrou casos de suicídios em que o motivo principal era a desestruturação da família depois da mudança para o Brasil, pois muitas vezes mecanismos de união das famílias não permaneciam mais nas relações no novo lar, tais como tradições religiosas e hábitos alimentares.

Considerando a anomia causada pela mudança de meio do imigrante, a vida do indivíduo fica desestabilizada, sem que haja uma sociedade organizada o suficiente que lhe dar o suporte necessário quando se encontra em dificuldades num ambiente estranho. Por isso, enxerga-se no suicídio uma forma de retorno à sua própria sociedade (SAITO, 1953). Essa é a conclusão de Saito, interpretando o ato final como um dos episódios que compõem o drama da mudança cultural e do processo de assimilação do imigrante, onde as culturas em conflito ficam no centro de suas vidas. Conflito este que é o foco dos estudos japoneses no Brasil na década de 1950, como veremos no artigo analisado na sequência.

\section{O estudo sobre grupos geracionais}

No início da década de 1950, Saito entra em contato com as Ciências Sociais japonesas e com o sociólogo japonês Seiichi Izumi, de quem foi assistente de pesquisa. Izumi é contratado pela UNESCO, em 1952, para realizar pesquisas no Brasil com o objetivo de investigar possíveis situações de conflitos entre imigrantes japoneses no país. Ele teria vindo ao Brasil, inicialmente, para pesquisar sobre a assimilação dos descendentes japoneses dentro do contexto de polarização dos imigrantes ao final da Segunda

6 Após apresentar alguns cálculos, Saito sugere que este número pode ser muito maior na realidade, pois muitos não seriam noticiados ou registrados como suicídio. 
Guerra. O foco principal seria investigar a criação e o funcionamento da Shindô-Renmei ${ }^{7}$ (KINGSBERG, 2014).

No início de 1953, Izumi e Saito fizeram pesquisas de campo no interior do Brasil, distribuindo questionários e entrevistando imigrantes. Uma das primeiras descobertas de suas pesquisas foi a conclusão de que $10 \%$ dos imigrantes ainda acreditavam na vitória do Japão na guerra. Em seu relatório, Izumi afirma que, no Brasil, os imigrantes e seus descendentes eram brasileiros no que concernia à educação, à língua e à religião. Ele conclui que imigrantes mais ricos e com maior nível educacional tendiam a aceitar a derrota do Japão e a assimilação. (KINGSBERG, 2014).

Parte da pesquisa está em artigo publicado em 1953, na revista Sociologia, escrito em coautoria com Saito, intitulado "Pesquisa sobre a aculturação dos japoneses no Brasil" (1953). Durante a coleta de dados, buscou-se entender os aspectos gerais das colônias, observando as suas características estruturais e econômicas. Os imigrantes pesquisados moravam em cidades dos estados de São Paulo, Paraná, Pará e Amazonas (IZUMI \& SAITO, 1953).

Foram distribuídos dois questionários. O primeiro perguntava as condições econômicas, com o intuito de conhecer a sua ascensão econômica antes, durante e depois da Segunda Guerra. O segundo tratava da estrutura da família. Neste, eram questionados temas relacionados à língua usada dentro de casa, ao contato mantido com os parentes no Japão, à nacionalidade e profissões de padrinhos. Também se perguntava sobre os hábitos religiosos dos imigrantes, revelando que $70,4 \%$ da população nipo-brasileira era budista, 20,4\% católica, 9,2\% protestante (IZUMI \& SAITO, 1953). Nesse mesmo sentido, o catolicismo teve um alto grau de penetração entre os jovens de 10 a 15 anos, e isso se daria, segundo os autores, pois

A alta porcentagem que ocupa o catolicismo no grupo de 10-15 anos é um indício de algo significativo: as crianças são batizadas em maior número durante o curso primário ou por ocasião da matrícula nas escolas, sendo esse fenômeno bem mais acentuado no após-guerra (IZUMI \& SAITO, 1953, p. 205)

A mudança de atitude dos imigrantes após a guerra ocorre pela impossibilidade de retornar ao Japão, sendo necessário, portanto, se fixar no Brasil. Além disso, as diferenças geracionais relacionadas à religião mostram a importância do contato das crianças imigrantes com a sociedade local na escola para o seu processo de assimilação. Assim, juntando as entrevistas, as observações de campo e os questionários, Izumi e Saito fazem uma análise dos "níveis" de assimilação entre os japoneses e seus filhos, considerando-se aqui tanto os que vieram muito jovens para o Brasil como os que nasceram aqui. Os autores percebem que os descendentes estariam mais assimilados à sociedade brasileira do que seus pais imigrantes, e havia um grupo de japoneses numa camada "marginal".

7 Carta de Hiroshi Saito a Cyro Berlinck. 20 de abril de 1953. Fonte: FDP/AEL/Unicamp. 
Isto é, a faixa etária acima dos 40 anos seria uma camada "japonesa", pois fora educada no Japão e seguia uma religião japonesa. Considerando o processo de interação de Park, entende-se que, neste grupo haveria o processo de competição, já que os indivíduos estariam em constante choque com a cultura brasileira pela dificuldade de mudarem determinados padrões culturais. Entre as pessoas de 25 a 40 anos, havia a predominância daquelas nascidas no Japão, mas prevalece a dualidade da cultura japonesa e brasileira; e esta seria justamente a "camada marginal". Este grupo estaria passando pelos processos de conflito e acomodação. Conflito porque eles estariam conscientes da luta que havia entre as duas culturas; e acomodação, pois eles já estariam mais ajustados a determinados padrões culturais e de comportamento da sociedade brasileira. Essas acomodações seriam aceitas e transmitidas para as gerações seguintes com mais naturalidade do que do primeiro para o segundo grupo (PARK \& BURGESS, 2014).

Por fim, os indivíduos com até 25 anos seriam o grupo "brasileiro", tendo todos nascidos no Brasil, e estando em contato com educação e religião brasileiras (IZUMI \& SAITO, 1953). Eles estariam no processo de assimilação, envolvendo-se no cotidiano da sociedade brasileira e frequentando suas escolas e igrejas, ou seja, estabelecendo um contato mais íntimo com os padrões culturais brasileiros e sofrendo, assim, transformações mais profundas em suas personalidades.

A classificação do segundo grupo de imigrantes, feita por Saito e Izumi, como "camada marginal", pode ser novamente relacionada ao conceito de "homem marginal", de Stonequist. Segundo o sociólogo norte-americano, indivíduos que vivem numa situação "bicultural" (ou "multicultural"), tendem a buscar adaptação no grupo que possui o maior prestígio e poder (STONEQUIST, 1935). No caso, os jovens japoneses na camada "marginal" tenderiam a seguir os padrões dos brasileiros, evidentemente hegemônico no território nacional. Stonequist ainda destaca que este era o melhor grupo focal para estudar a mudança cultural, pois a sua história de vida poderia oferecer um método de estudo do processo cultural. Valendo-se dos termos de Park, o intelectual conclui: "é na mente do homem marginal — onde as mudanças e fusões de culturas estão acontecendo — que nós podemos melhor estudar o processo de civilização e progresso" (PARK, s/d in STONEQUIST, 1935).

As diferenças geracionais presentes no artigo mostram uma das formas de se abordar o processo de assimilação entre imigrantes. Neste tipo de abordagem os focos das observações e análises centram-se nos conflitos de língua, educação ou normas culturais. Assim, é importante considerar as diversas experiências entre diferentes gerações, principalmente entre crianças e adultos.

\section{Considerações finais}

Ao apresentar estes três textos de Hiroshi Saito, os quais ele publica quando ainda era estudante, procuro mostrar a sua preocupação em entender o processo de assimilação do imigrante japonês à sociedade brasileira entre as décadas de 1940 e 1950. Contudo, 
para além da sua preocupação acadêmica com o tema, é importante destacar que Saito era um imigrante que se formou sociólogo no Brasil e investigou por muitos anos o processo de inserção de sua comunidade na sociedade brasileira. Seu engajamento com a produção de conhecimento não parava nas publicações acadêmicas. A partir de meados da década de 1960 até pouco antes de seu falecimento, em 1983, Saito participava de palestras e eventos que ocorriam na comunidade japonesa, geralmente para discutir a economia, aspectos socioculturais e as possibilidades de desenvolvimento do setor agrícola. Também costumava falar sobre a assimilação, onde seria difícil enxergar o limite entre a integração dos descendentes na sociedade brasileira e a perda das especificidades da cultura nipônica (CASTRO, 1994; COTRIM, 2016).

Nos três artigos aqui discutidos, Saito, e seus coautores, destacam tanto a assimilação como a não assimilação dos imigrantes japoneses à sociedade brasileira. No artigo de 1947, escrito com Willems, ele analisa o grupo que mais se destacou entre os japoneses como contra a assimilação, mas também chama a atenção para aqueles que lutaram contra o extremismo nacionalista japonês. Ao tratar dos casos de suicídio, Saito mostra como o isolamento forçado pelas leis de nacionalização do Estado Novo e a oposição ao nacionalismo extremo japonês levaram a casos de suicídio. No texto, ele argumenta que o ato seria uma forma de reforçar a sua identidade de origem, e mostra que, entre aqueles mais bem assimilados, havia menos de casos de suicídio. Por fim, no artigo com Izumi, talvez o mais militante dos três, fica clara a defesa pela assimilação dos imigrantes japoneses, apresentando as vantagens daqueles já assimilados, como o domínio da língua local, maiores oportunidades de estudos e trabalhos, e consequentemente, melhores condições de vida. Isso também mostra a comprovação do que Saito mais militava: os imigrantes japoneses eram passíveis de assimilação à população brasileira, assim como outros grupos estrangeiros que aqui chegaram.

Em nenhum de seus trabalhos Saito trata diretamente do preconceito e da repressão enfrentadas pelos japoneses durante a Segunda Guerra, apesar de abordar pontualmente a reação de alguns membros da comunidade japonesa em função desses acontecimentos. No entanto, fica claro que Saito milita em defesa dos japoneses e dos imigrantes em geral, buscando comprovar a assimilação e os benefícios da sua presença no Brasil. Todos os seus estudos defendem, de alguma forma, que foi positivo para o país receber imigrantes, por mais que não tenha sido uma adaptação fácil. Saito ainda mostra que os japoneses (e não só) seriam capazes de se assimilar, passando pelo processo que "resultaria" na presença de traços de ambas as culturas envolvidas na personalidade do indivíduo estrangeiro. Entre as vantagens de ter recebido estes imigrantes, ele destaca o desenvolvimento de novas técnicas agrícolas, introdução do cooperativismo no meio rural, e mudanças positivas de hábitos alimentícios nas cidades ${ }^{8}$.

De certo modo, ao fazer isso, Saito está buscando também o seu lugar como indivíduo estrangeiro pertencente a um grupo que, especialmente entre as décadas de

8 Tal ponto é amplamente tratado por Saito em sua dissertação de mestrado, analisada por Cotrim, 2016. 
1920 e 1940, foi menosprezado e alvo de críticas por parte da opinião pública brasileira. Na sua vida pessoal, ele tinha passado pelo processo de assimilação descrito e colocado em prática a ideia de que a comunidade japonesa deveria se ajudar ao fazer palestras e eventos voltados para os imigrantes e seus descendentes. Sobre essa junção do interesse pessoal ao intelectual, Saito escreve:

Como filho de imigrante, cuja família - como tantas outras que para aqui vieram quer da Europa quer da Ásia — buscar nesta terra vida humilde mas pacífica, despertou em mim desde cedo o interesse de observar a situação e viver a sensação daqueles que experimentam a vida do imigrado. Era como que um privilégio de que eu poderia lançar mão, na tentativa daquilo que o antropólogo ou sociólogo tem de interesse perene: compreender o semelhante. (SAITO, 1961, p. 7)

É interessante perceber que Saito se identifica enquanto filho de imigrante, mas não necessariamente como um. Suponho que ele se identificava menos como imigrante, e mais como membro da camada marginal localizada por ele e Izumi no trabalho de 1953. A categoria, conforme definida pelos autores, referia-se a pessoas que ou nasceram aqui logo que os pais chegaram, ou emigraram ainda jovens (no caso, ele tinha 14 anos), conservando alguns traços da cultura japonesa e adotando outros da brasileira. Estes indivíduos estariam entre os dois mundos, dominavam ambas as línguas, mas sofriam, pois sentiam que não pertenciam a nenhum dos dois. Além disso, conforme Stonequist (1935) destaca, os indivíduos marginais tenderiam a buscar mais frequentemente a cultura hegemônica do que de origem. No caso do imigrante ou do descendente japonês, haveria a preferência em adotar hábitos brasileiros para facilitar a sua inserção na sociedade local. Isso gerava conflitos dentro das famílias, sobretudo com pessoas mais velhas que se mantinham ligadas à cultura de origem e cobravam o mesmo comprometimento dos filhos. Com isso em mente, é compreensível a preocupação de Saito com os conflitos geracionais entre os imigrantes, seus descendentes e a sociedade local.

Logo, Saito é um exemplo da sua própria definição de assimilação, mesclando características das culturas japonesa e brasileira, para se firmar enquanto sociólogo especialista em estudos sobre japoneses no Brasil. Além disso, a sua própria presença, como aluno e professor numa prestigiada instituição acadêmica do país, comprova que ele se assimilou à sociedade dominante, aderindo aos costumes do meio universitário local, como escrever em português, por exemplo. Por outro lado, ao focar seus estudos nos imigrantes, reforça para si e para outros as suas origens.

Saito faz uso dos instrumentos da Sociologia e da Antropologia brasileiras para compreender a sociedade ao seu redor, os grupos se inserem nela e os processos pelos quais ele e outros imigrantes passavam, buscando formas de minimizar os traumas da assimilação. Dessa maneira, ao estudar a imigração japonesa no Brasil, ele está se reafirmando tanto como imigrante japonês como sociólogo brasileiro. 


\section{Referências Bibliográficas}

BASTIDE, Roger. Os suicídios em São Paulo, segundo a cor. Boletim de Sociologia da USP, São Paulo, USP, n.71, p. 1-49, 1951.

COTRIM, Aline. Imigração e assimilação nos estudos sociológicos de Hiroshi Saito (19471964). Dissertação (Mestrado em História das Ciências e da Saúde) - FIOCRUZ, Rio de Janeiro, 2016.

COULON, Alain. L'École de Chicago. Paris: PUF, 1992.

DURKHEIM, Emile. Le Suicide. Paris: Quadrige/ PUF, 2002.

HATANAKA, Maria Lucia E.. O Processo Judicial da Shindô-Renmei: um fragmento da história dos imigrantes japoneses no Brasil. São Paulo: Fund. Japão, Annablume Ed., 2002.

IZUMI, Seiichi. SAITO, Hiroshi. Pesquisa sobre a aculturação dos japoneses no Brasil. Sociologia, v.15, n.3, p. 451-462, 1953.

KINGSBERG, Miriam. Becoming Brazilian to Be Japanese: Emigrant Assimilation, Cultural Anthropology, and National Identity. Comparative Studies in Society and History, v.56, n.1, p. 67-97, 2014.

PARK, Robert. BURGESS, Ernest. Competição, conflito, acomodação e assimilação. Revista Brasileira de Sociologia da Emoção, v.13, n.38, p. 129-138, agosto 2014.

PIERSON, Donald. Resenhas Bibliográficas. Sociologia, v.25, n.2, p. 163-169, 1963.

SAITO, Hiroshi. O suicídio entre os imigrantes japoneses e seus descendentes no Estado de São Paulo. Sociologia, v.15, n.2, p. 109-130, 1953.

SAITO, Hiroshi. O Cooperativismo na Região de Cotia: estudo de transplantação cultural. São Paulo: Escola de Sociologia e Política de São Paulo, 1956.

SAITO, Hiroshi. O Japonês no Brasil: estudo de mobilidade e fixação. São Paulo: Ed. Sociologia e Política, 1961.

SEYFERTH, Giralda. A assimilação dos imigrantes como questão nacional. Mana, Rio de Janeiro, v.3, n.1, p. 95-131, 1997.

STONEQUIST, Everett. The Problem of the Marginal Man. American Journal of Sociology, v.41, n.1, p. 1-121, julho 1935.

TANIGUTI, Gustavo. Cotia: imigração, política e cultura. Tese (Doutorado em Sociologia), USP, São Paulo, 2015.

TANIGUTI, Gustavo. JESUS, Matheus. Sociologie de l'immigrant: Hiroshi Saito et 1'institutionalisation des études sur les Japonais du Brésil (1940-1960). Brésil (s), v.2, p. 201-224, 2012.

WILLEMS, Emilio. SAITO, Hiroshi. Shindô-Renmei: um problema de aculturação. Sociologia, v.9, n.2, p. 133-152, 1947. 